\title{
Economia solidária e saúde mental: um relato sobre práticas de inclusão pelo
}

\section{trabalho}

\author{
Solidarity economy and mental health: a report on work inclusion practices \\ Economía solidaria y salud mental: informe sobre prácticas de inclusión en el trabajo
}

Recebido: 11/08/2021 | Revisado: 15/08/2021 | Aceito: 17/08/2021 | Publicado: 20/08/2021

\author{
Felipe Roberto Ribeiro Sampaio \\ ORCID: https://orcid.org/0000-0003-1892-0692 \\ Universidade Federal do Paraná, Brasil \\ E-mail: to.feliperoberto@gmail.com \\ Luís Felipe Ferro \\ ORCID: https://orcid.org/0000-0001-8935-104X \\ Universidade Federal do Paraná, Brasil \\ E-mail: luisfelipeferro@gmail.com
}

\begin{abstract}
Resumo
O objetivo deste artigo é relatar a experiência advinda de um projeto de extensão coordenado pela Universidade Federal do Paraná, apresentando algumas das potencialidades, barreiras e estratégias adotadas para o fortalecimento do processo de estruturação de um empreendimento solidário vinculado a um Centro de Atenção Psicossocial do Paraná. O relato de experiência se utilizou, enquanto técnica de coleta de dados, de anotações sistemáticas em diário de campo, realizadas entre agosto de 2018 e julho de 2019. Os dados foram analisados sob a perspectiva da análise hermenêutico dialética. A partir do relato, pode ser visualizada uma experiência de construção gradual da prática de inclusão pelo trabalho, ancorada: na vivência de dificuldades e potencialidades próprias ao trabalho em rede, assumindo a importância da construção orgânica e humana de parcerias institucionais diversas; em ações de construção de conhecimento sobre Economia Solidária; na vinculação e construção de relações com redes locorregionais de Economia Solidária; na importância do compromisso com a garantia do direito ao trabalho; na edificação de ações de educação popular para a Economia Solidária; na necessidade da construção e utilização de dispositivos que promovam o cuidado territorial, sublinhada a contribuição do acompanhamento terapêutico. Portanto, destaca-se ainda a necessidade de políticas públicas que provejam tanto estrutura e apoio para o desenvolvimento dos empreendimentos solidários, como cuidado em Saúde Mental, de maneira a garantir condições propícias para a inclusão social pelo trabalho de pessoas em sofrimento mental.
\end{abstract}

Palavras-chave: Saúde mental; Trabalho; Renda; Inclusão social; Políticas públicas; Saúde pública.

\begin{abstract}
The current Mental Health public policy presents as one of its objectives the investiture in the inclusion of people with mental disorders through work. In this context, a fruitful partnership has been established with Solidarity Economy. The objective of this article is to report the experience arising from an extension project conducted by Federal University of Paraná, presenting potentialities, barriers and the strategies adopted for structuring a solidary enterprise situated in the interface with Mental Health. The experience report was structured from the analysis, based on the hermeneutic-dialectic perspective, of field diary, carried out between August 2018 and July 2019. From the report, it is highlighted: the difficulties and potentialities inherent to networking, assuming the importance of the organic and human construction of different institutional partnerships; several actions to build knowledge on Solidarity Economy; the importance of building relationships with locoregional Solidarity Economy networks; the need of the commitment to guaranteeing the right to work; actions to build popular education in Solidarity Economy; the need to build and use devices that promote territorial health care, underlining the contribution of therapeutic accompaniment. Therefore, the need for public policies that provide both structure and support for the development of solidary enterprises and for community care is also highlighted, in order to guarantee conditions for social inclusion of people with mental disorders through the work.
\end{abstract}

Keywords: Mental health; Public policy; Work; Solidarity economy; Social inclusion; Public health.

\section{Resumen}

El objetivo de este artículo es reportar la experiencia surgida de un proyecto de extensión coordinado por la Universidad Federal de Paraná, presentando algunas de las potencialidades, barreras y estrategias adoptadas para fortalecer el proceso de estructuración de um emprendimiento solidário vinculado a un Centro de Atención Psicosocial de Paraná. El relato de experiencia se utilizó, como técnica de recolección de datos, de anotaciones 
sistemáticas en un diario de campo, realizado entre agosto de 2018 y julio de 2019. Los datos fueron analizados desde la perspectiva del análisis hermenéutico dialéctico. Del informe se desprende una experiencia de construcción paulatina de la práctica de la inclusión a través del trabajo, anclada en: la experiencia de las dificultades y potencialidades inherentes al trabajo en red, asumiendo la importancia de la construcción orgánica y humana de diferentes alianzas institucionales; en acciones de construcción de conocimiento en Economía Solidaria; en vincular y construir relaciones con redes locorregionales de Economía Solidaria; sobre la importancia del compromiso de garantizar el derecho al trabajo; en la construcción de acciones de educación popular para la Economía Solidaria; sobre la necesidad de construir y utilizar dispositivos que promuevan el cuidado territorial, destacando la contribución del acompañamiento terapéutico. También se destaca la necesidad de políticas públicas que proporcionen estructura y apoyo al desarrollo de emprendimientos solidarios, así como a la atención a la salud mental, a fin de garantizar condiciones favorables para la inclusión social a través del trabajo de las personas en sufrimiento mental.

Palabras clave: Salud mental; Trabajo; Economía solidaria; Inclusión social; Políticas públicas; Salud pública.

\section{Introdução}

A Economia Solidária é um modelo para o desenvolvimento econômico, socioambiental e cultural que, alicerçado nos princípios da autogestão, cooperação e solidariedade, afirma como seu maior valor os seres humanos e suas relações entre si e com o meio ambiente (Santos, 2018). Enquanto proposta de organização societal do trabalho, a Economia Solidária visa desvanecer os efeitos adversos irradiados do modo capitalista de produção sobre a vida das pessoas (Ferreira, 2018).

Desta forma, a Economia Solidária se ancora no resgate da cidadania e da democracia, possibilitando a construção conjunta de empreendimentos gerenciados por seus trabalhadores. Estruturada por meio de grupos de trabalho, cooperativas, associações, bancos comunitários ou redes colaborativas, a Economia Solidária favorece a congregação e organização de coletivos de trabalhadores para a produção de produtos e serviços, tendo como um de seus pilares a autogestão (Souza \& Augusto Júnior, 2020).

Portanto, em sua proposta, a Economia Solidária em si mira superar um simples caráter paliativo para o desemprego, avançando para o real resgate da cidadania, de mútuo gozo da igualdade de direitos, da liberdade, com respeito às opiniões individuais e valorização do coletivo (Almeida, 2018). Contudo, esses empreendimentos vivenciam cotidianamente diferentes fragilidades, que tangenciam: carências de políticas públicas que promovam sua consolidação e fortalecimento; a falta de capacitações e apoio para a especialização de seus processos produtivos e de gestão; a incipiência de linhas de créditos específicas, voltadas a propulsionar os empreendimentos solidários; a falta de amparo para promover a comercialização de seus produtos e serviços; entre outras (Martins, 2017; Silva, 2020).

Neste cenário, as Redes Solidárias podem proporcionar, por meio da congregação de diferentes potências institucionais e comunitárias: a organização/especialização de processos de trabalho; a formação e qualificação da produção; a ampliação de estratégias de comercialização; a criação e manutenção de redes colaborativas de consumo e arranjos produtivos diversificados e criativos; a captação de recursos para desenvolvimento das diferentes ações; entre outras ações (Aguiar \& Filho, 2018; Ferro, Franzoloso, \& Burnagui, 2020).

Frente a isso, as políticas públicas determinam o papel do Estado em relação aos conflitos sociais, dentre os quais as fragilidades enfrentadas pelos empreendimentos, redes e coletivos solidários em suas atividades e estruturação (Aguiar \& Filho, 2018). Ao favorecerem a intersetorialidade e a transversalidade em suas disposições, é composta arena para fortalecimento de iniciativas de trabalho e geração de renda.

No contexto brasileiro, o campo da Saúde Mental se destaca por sua sensibilidade no que refere à consideração de diferentes fatores que influenciam o processo de saúde e doença de seu público-alvo. A atual política nacional de Saúde Mental, conhecida por Rede de Atenção Psicossocial (RAPS), procura promover estratégias que aliem indissociavelmente o cuidado clínico a propostas de inclusão social e participação comunitária de pessoas em sofrimento mental. Um dos objetivos desta política, neste panorama, é promover apoio e cuidado comunitário a pessoas em sofrimento mental no percurso de sua 
inclusão na vida produtiva. Enquanto propostas, desta forma, a RAPS prevê a construção, apoio e assessoria a empreendimentos solidários voltados à geração de trabalho e renda que incluam sua população-alvo.

A partir desta interface, diferentes pontos de atenção da RAPS, especialmente os Centros de Atenção Psicossocial (CAPS), vêm promovendo propostas voltadas a fortalecer possibilidades de inclusão produtiva, tendo como base estrutural os princípios e propostas da Economia Solidária (Oliveira, Moreira, Lima Junior, Nascimento, Silva, \& Antunes, 2018). Assim, é previsto que profissionais e serviços vinculados à RAPS estendam seu suporte aos usuários sobre o território para uma atenção em rede e integral, articulando os serviços de saúde com outros serviços públicos, privados e comunitários. A comunicação e o estabelecimento de parcerias em uma rede intersetorial que favoreça o cuidado e o acesso dos usuários ao trabalho e a renda potencializa seus objetivos e intervenções na produção de um cuidado qualificado (Brasil, 2011; Brasil, 2017; Araújo \& Soares, 2018).

Neste contexto, o objetivo do presente estudo é relatar a experiência do projeto de extensão "Centro de convivência: cidadania e geração de renda", desenvolvido pela Universidade Federal do Paraná, foco dado à análise das potencialidades, barreiras e estratégias adotadas para o fortalecimento do processo de estruturação de um empreendimento de Economia Solidária, apoiado por um Centro de Atenção Psicossocial Álcool e Drogas III (CAPS ad III) do estado do Paraná e inserido em uma Rede Locorregional de Saúde Mental e Economia Solidária. Pretende-se, desta forma, contribuir para o aprofundamento sobre as práticas em Saúde Mental em confluência com o campo da Economia Solidária.

\section{Metodologia}

O relato da experiência do projeto de extensão em tela pretende apresentar de maneira qualitativa (Pereira et al., 2018), descritiva e reflexiva o processo colaborativo desenvolvido junto a um empreendimento solidário apoiado por um CAPS AD III do Paraná. A participação se deu no período de agosto de 2018 a julho de 2019, procurando analisar as diferentes barreiras vivenciadas por tal empreendimento, suas potencialidades, assim como as estratégias executadas para fortalecer a iniciativa.

Para a coleta e sistematização dos dados advindos da vivência extensionista, foi utilizado o instrumento diário de campo. Por meio desta técnica, foram compiladas as dimensões reflexiva e descritiva das vivências, submetendo-as a categorização e análise (Mazucato, Zambello, Soares, Tauil, Donzelli, Fontana, \& Chotolli, 2018).

Para compor o guia para a análise dos dados, foi utilizado o escopo proposto pela análise hermenêutico-dialética. Enquanto a hermenêutica trata da interpretação do valor e dos significados das perspectivas, narrativas, conflitos e demais nuances das dimensões temporais e pessoais que compõem cena junto ao contexto vivido (Damasceno, Malvezzi, Sales, \& Sales, 2018), a perspectiva dialética, por sua vez, parte do princípio da determinação multifacetada das experiências na busca por dialogar com o contexto histórico e estrutural em que os fenômenos tomam lugar (Damasceno, Malvezzi, Sales, \& Sales, 2018; Righi \& Gonçalves, 2018).

Desta forma, pôde-se analisar a experiência extensionista, de maneira a apresentar e refletir criticamente sobre as vivências em uma espiral evolutiva. Assim sendo, tal análise culminou na exposição de uma contextualização inicial seguida pela elaboração das seguintes categorias: Arranjos Institucionais; Educação Popular e Economia Solidária; Políticas Públicas e Economia Solidária; e Produção e Venda.

Para preservar a identidade dos envolvidos, os 45 usuários que participaram do grupo ao longo do período estão aqui referidos pela letra $\mathrm{U}$ seguida de um número que o identifique entre 1 e 45; os profissionais serão identificados pela letra $\mathrm{P}$ seguida de um número; e as coordenadoras estão identificadas pela letra $\mathrm{C}$ seguida de um número. 


\section{Resultados e Discussão}

Economia solidária e centros de atenção psicossocial: contextualizações e processos iniciais para a constituição da iniciativa

Os Centros de Atenção Psicossocial (CAPS) são serviços previstos pela RAPS, constituídos como uma das portas de entrada do SUS (Amarante \& Nunes, 2018; Brasil, 2011). Desde o final dos anos 1980, estes dispositivos prestam atendimento às pessoas com transtornos mentais e ou com necessidades de saúde decorrentes do uso de crack, álcool e outras drogas, dispondo de ações clínicas, psiquiátricas e de reinserção social pelo trabalho, lazer, cidadania e recomposição de vínculos comunitários e familiares (Araújo \& Soares, 2018). Neste cenário, a Economia Solidária enquanto estratégia de trabalho e geração de renda vem sendo historicamente uma das tônicas no rol de dispositivos do CAPS para inserção social (Oliveira et al., 2018; Amarante \& Nunes, 2018).

Neste cenário, grupos de geração de trabalho e renda, pautados na Economia Solidária, vêm se estabelecendo historicamente como uma das tônicas no rol de serviços providos pelos CAPS (Oliveira et al., 2018; Amarante \& Nunes, 2018; Moraes \& Castro-Silva, 2016). Porém, no município de inserção do CAPS vinculado às ações extensionistas esta conduta é ainda tímida, figurando algumas experiências recentes que compartilham diferentes barreiras. As ações de extensão foram voltadas aos usuários, profissionais, coordenação e território.

Especificamente no CAPS em voga, não havia ação de trabalho e geração de renda vigente à época do início das intervenções ou mesmo apoio do CAPS a iniciativas de geração de trabalho e renda. Entretanto, em momento pregresso, a instituição proveu suporte a um empreendimento, o qual foi desarticulado por diferentes situações, entre elas as mudanças de profissionais do serviço. Procurando retomar a investidura da instituição em iniciativas voltadas à inclusão social pelo trabalho, em primeiro momento foram desenvolvidas ações voltadas aos usuários, profissionais, coordenação e determinados pontos do território do CAPS, tendo como objetivo sensibilizar estes agentes e construir conhecimento junto ao tema da Economia Solidária.

Em primeiro contato, em proposição da iniciativa com os usuários, foi pactuada a criação de um empreendimento tendo como atividade fim a produção alimentícia. As ações definidas para enfrentar coletivamente as problemáticas quanto à inclusão pelo trabalho de diferentes usuários do CAPS tiveram como foco inicial a promoção de ações de educação popular em Economia Solidária com os usuários, mobilização da equipe e gestão para caracterização e viabilização da estratégia de trabalho e geração de renda na instituição, ações de articulação de políticas públicas para conquista de cozinha enquanto espaço de produção e estabelecimento de produção e venda.

Dos usuários, U7, U9, U16, U17, U18, U19, U20, U22, U24, U28, U29, U30, U33, U36 e U38 compareceram apenas uma vez no grupo de Educação Popular, mas não deram continuidade à participação na iniciativa de geração de trabalho e renda. Os usuários U10, U23, U26, U27, U33, U34, U39, U42 e U43 eram do sexo feminino e somente U3, U42 e U45 cursaram ensino superior. Os demais, em sua maioria, não possuíam ensino fundamental completo. U22, U23, U27 e U35 já haviam participado de empreendimentos solidários e, com exceção de U3 e U33, todos estavam desempregados.

\section{Economia solidária e arranjos institucionais: a viabilização de possibilidades}

As ações começaram buscando compor com a equipe do serviço ações conjuntas para o desenvolvimento do empreendimento. Entretanto, inicialmente P1 e P2 mantiveram distância das práticas alegando sobrecarga, falta de tempo e conflitos com a equipe. A proposta inicial de organizar o grupo duas ou três vezes por semana não foi aceita, sendo possibilitada sua realização somente em um dos dias da semana, entre as 9 e 10 horas da manhã, concomitantemente à reunião da equipe, momento em que o CAPS não ofertava atividades aos usuários de seus serviços. 
Neste momento, além de haver reformulações na agenda do CAPS, o serviço estava passando por um período de instabilidade devido a mudanças na configuração dos CAPS na cidade, que repercutiram na composição da equipe que estava constantemente sofrendo remanejamento para outros pontos do município. Perante isto, as profissionais relataram estar ansiosas e preocupadas com a sua situação e as ações de trabalho e geração de renda foram conduzidas inicialmente apenas pelo extensionista.

P1 e P2 arguiram que as quartas-feiras são dias de reunião de equipe, sendo o melhor dia da semana não apenas para evitar interferência em outras agendas do CAPS, mas também para oferecer um grupo em um dia no qual não haviam outros grupos sendo ofertados. Entretanto, a ação no CAPS em Economia Solidária começa à margem das práticas dos profissionais do serviço, pois estando em reunião, não se envolveram, em primeiro momento, diretamente nas ações. (Sampaio, 10 de agosto de 2018).

A partir deste contexto, a primeira ação adotada foi procurar sensibilizar a equipe do CAPS. Na sensibilização buscase a problematização da importância do trabalho em direção a um objetivo comum. Entretanto, este enfrentamento deve ser permeado por um cuidado tecido com sutileza, mansidão, delicadeza e reverência (Lima, Gussi, \& Furegato, 2018). A exposição da equipe ao assunto da Economia Solidária em sua rotina, acompanhada de estratégias para a percepção da importância e necessidade de sua agência e cooperação para este trabalho despertou interesses e curiosidades acerca das ações a serem desenvolvidas pelo projeto (Sampaio, 12 de dezembro de 2018).

Assim, o extensionista organizou sua conduta de modo a transmutar uma ação antes vista como universitária para uma ação do serviço desenvolvida pela equipe, com apoio da universidade. Para tanto, através de reuniões para discussão de possibilidades de composição de um trabalho em rede envolvendo equipe, coordenação e extensionista, e de organização do discurso, foi estruturada uma nova possibilidade de trabalho (Sampaio, 08 de janeiro de 2019).

Neste processo, em uma nova configuração, o grupo teve duração das $8 \mathrm{~h} 30$ às $11 \mathrm{~h} 30$, às segundas, quartas e sextasfeiras, tendo por referência P1, o extensionista e P2 para cada um destes dias respectivamente. Mas para isso, foi necessário costurar alguns combinados com $\mathrm{C} 1$ em relação a rotina de trabalho de P1 e P2 para que estas não ficassem sobrecarregadas. Assim, a equipe passou a ter outro conceito do grupo, inclusive P3 e P4 que prestaram algumas importantes contribuições técnicas diretas ocasionais de suporte ao grupo (Sampaio, 08 de janeiro de 2019).

Paralelamente, em ações articuladas em rede de trabalho, a oportunização desta experiência se deu pela construção histórica de um contexto com espaço propício para iniciativas de trabalho e geração de renda em saúde mental. Ações mobilizadas como sensibilização de gestores, relatórios de Conferências de Saúde e Economia Solidária, eventos científicos e de capacitação técnica para profissionais da área, acionamento do Ministério Público e incidência política de cobrança das Leis municipal e estadual de Economia Solidária abriram caminho para estabelecer esta experiência (Sampaio, 31 de janeiro de 2019).

Além disso, para captação de recursos no território, com maior aproximação entre o extensionista e C1, foi redigido um novo projeto que, submetido a revisão de C1, P1 e P2, recebeu o timbre do CAPS. Em relação a coordenação, havia insegurança em seu envolvimento com esta iniciativa, pois havia um receio de eventuais consequências de seu apoio por parte de outros gestores hierarquicamente superiores, uma vez que não era um procedimento de praxe no serviço. Para superar esta barreira, houve sensibilização em diversas ocasiões para os precedentes da Economia Solidária em Curitiba e Região e do apoio destes gestores, que prosperou encorajamento para parceria nesta e outras ações (Sampaio, 08 de fevereiro de 2019).

Por fim, a população com dependência química em tratamento em CAPS possui a tendência, como referido por P1 (Sampaio, 11 de agosto de 2018), de serem inconstantes e não aderirem ao tratamento, o que faz com que a maioria dos grupos no equipamento passe por momentos de baixa participação e constante movimentação de membros. Para tratar esta questão, 
além de favorecer uma inclusão social mais efetiva, o extensionista buscou com as profissionais e a coordenação articular o CAPS com outros equipamentos do território, como UAI (Unidade de Acolhimento Institucional), CRAS (Centro de Referência de Assistência Social), Conselho da Comunidade e Associação de Moradores, para acolher pessoas de diversos pontos para suprir em parte as eventuais baixas que o grupo no CAPS pudesse sofrer em relação aos usuários que recaíssem e ou abandonassem o tratamento (Sampaio, 08 de janeiro de 2019).

A Lei ${ }^{\circ} 8.080$ de 1990, que regula o Serviço Único de Saúde (SUS) em território nacional, define fatores determinantes e condicionantes sociais de saúde, dentre os quais o trabalho e a renda. Neste sentido, dentro do SUS, a Rede de Atenção Psicossocial (RAPS), conforme a Portaria do Ministério da Saúde nº 3.088 de 2011, assenta iniciativas de geração de trabalho e renda por via da Economia Solidária, como elementares dentro do componente Reabilitação Psicossocial. Na organicidade do cuidado dirigido aos usuários da RAPS, é instituída a Economia Solidária em seus equipamentos como Centro de Atenção Psicossocial de Álcool e outras Drogas III (CAPS ad III) conforme Portaria no 130 de 2012, Unidade de Acolhimento (UA) consoante a Portaria $\mathrm{n}^{\circ} 121$ de 2012, Comunidades Terapêticas segundo a Portaria $\mathrm{n}^{\circ} 131$ de 2012, e o Serviço Residencial Terapêutico (SRT) do Tipo 1 conforme a Portaria nº 3.588 de 2017.

Entretanto, a distância entre o contexto preconizado e o contexto real afasta a concretude de ações de trabalho e geração de renda efetivamente prestadas pela Rede de Atenção Psicossocial. Ao longo do processo, foram identificados fatores diversos que podem contribuir para a fragilização e desprovimento destas ações, como crise fiscal, alternâncias de políticas de governo, formação profissional, ausência de plano de carreira e estabilidade para profissionais de fundações estatais, rotatividade do quadro de profissionais e gestores, problemáticas em dinâmicas de equipe, dentre outros. Para o profissional atuar nesta área, não apenas no campo da Economia Solidária, como também em outras ações, é necessário sistematizar uma prática em meio a estas estruturas micro, meso e macro organizacionais.

As posições hierárquicas presentes no segmento de gestores e profissionais devem ser consideradas em uma relação delicada, que pode servir de apoio ou barreira ao trabalho em Economia Solidária e Saúde Mental. A lentidão que processos burocráticos para o andamento da estruturação de empreendimentos solidários, como a captação de recursos, otimização de processos de trabalho como a adoção de prontuário eletrônico, aquisição de espaço e a reserva de carga horária de profissionais do serviço é um desafio a ser superado no campo da gestão, além de ações efetivas de parcerias intersetoriais e interinstitucionais.

Na carta final da V Plenária Nacional de Economia Solidária, de 2013, instância máxima de deliberação do Fórum Brasileiro de Economia Solidária, que contou com a presença do seguimento da Saúde Mental, chama a atenção para a importância de implementar processos de trabalho na intersecção entre estes dois campos que valorizam e sistematizam saberes e tecnologias. Além disso, destaca a necessidade de associação entre cultura, identidade e expressões de solidariedade em ações formativas sobre Saúde Mental (Nagem \& Jesus, 2013).

\section{Educação popular e economia solidária: construções de bases para o cotidiano}

Com os usuários, as ações de formação da iniciativa produtiva se deram a partir de um processo de educação popular. A educação popular deve voltar-se para a transformação social através da valorização da leitura da realidade por meio da reflexão e do diálogo entre saberes, abarcando as dinâmicas do território em suas diversas dimensões (Medeiros, Vilaça, Nunes, \& Dubeux, 2018) .

No que tange à Economia Solidária, são importantes ações constantes que promovam a educação popular, tendo como um de seus propósitos construir conhecimento teórico-prático que possibilite sedimentar operacionalmente, na realidade dos empreendimentos, seus princípios e valores, tais quais: a autogestão; a solidariedade; a cooperação entre os empreendedores e 
empreendimentos; e a sustentabilidade (Medeiros, Vilaça, Nunes, \& Dubeux, 2018). Com isso, busca-se também produzir assimilação e generalização por parte dos educandos em suas relações uns com os outros, com o ambiente e com a sociedade.

Entretanto, o momento político no qual o Brasil se encontrava entre setembro e dezembro de 2018 impôs algumas barreiras a esta intervenção. No serviço, conforme percebido cotidianamente, a Economia Solidária teve sua imagem associada ao socialismo e ao comunismo, uma perspectiva influenciada pelo período de polarização que as eleições presidenciais trouxeram consigo. Alguns comentários negativos e de desinteresse pela iniciativa começaram a aparecer entre usuários e por parte de alguns profissionais, que reverberam negativamente sobre as ações em economia solidária neste período. Embora a economia solidária compartilhe de alguns preceitos do socialismo como a propriedade coletiva e a igualdade, ela vai além, incorporando valores independentes como a democracia, a sustentabilidade ambiental e a solidariedade, o que lhe atribui um caráter singular.

Na literatura, são escassos os referenciais teóricos específicos sobre educação popular para Economia Solidária no Brasil. Entretanto, as práticas pedagógicas nesta área são permeadas principalmente pela Teologia da Libertação e pela Pedagogia da Autonomia e do Oprimido de Paulo Freire (Gontijo \& Paula, 2019). Neste sentido, a fim de descolar a imagem da economia solidária das discussões e perspectivas inflamadas pelas tensões político-partidárias daquele momento, o extensionista lançou mão da teoria dos jogos como referencial.

Com base principalmente nas contribuições do matemático John Nash, a teoria dos jogos é resumidamente a compreensão de que os jogos das relações humanas podem ser enquadrados entre dois modelos: os jogos competitivos e os cooperativos. Enquanto os jogos competitivos constituem-se na promoção do ganho de um indivíduo sobre os outros e engendra valores como o individualismo e o egoísmo, os jogos cooperativos caracterizam pela cooperação para o ganho mútuo e solidário (Vitale \& Silva, 2017). Os jogos cooperativos são dinâmicas de grupo que, simulando uma minissociedade, têm o objetivo de despertar a consciência dos participantes para a cooperação, respeito mútuo e a solidariedade, contribuindo significativamente para uma metodologia pedagógica que vise elaborar conteúdos atitudinais humanizados que, baseados na experiência vivida, possam ser generalizados para as demais relações sociais (Silva, 2018; Santos, 2017).

Assim, foram planejadas atividades de dinâmicas em grupo que, sob os moldes dos jogos cooperativos, proporcionam reflexões e fazeres conjuntos, elaborando os princípios da autogestão, da cooperação e da solidariedade. Com a valorização, pelos usuários, do espaço de produção de sentido que o grupo criava, o tempo do grupo evoluiu de uma para duas horas semanais, nas quartas-feiras.

Durante as vivências, percebeu-se que as reuniões mediadas por estas atividades prosperaram com maior efeito em relação às simples rodas de conversa, que por sua vez favoreceram a divagação por conteúdos pessoais que demandaram outro tipo de acolhimento. No entanto, a grande rotatividade de usuários devido a recaídas e a inicial dificuldade no trabalho em rede foram obstáculos a serem manejados. Para ambas as problemáticas, foi desenvolvida com P1 e P2 a busca ativa dos usuários faltantes, que representou um dos primeiros passos na aproximação efetiva das práticas da equipe com o grupo. Ademais, ações de promoção de habilidades sociais, feedback, feedforward e o manejo de crises foram administradas com o grupo, favorecendo seu desenvolvimento (Sampaio, 09 de outubro de 2018).

Ao fim deste ciclo, poucos usuários permaneceram no grupo, pois a maioria recaiu e ou abandonou o tratamento. Apesar da recaída e ou descontinuidade serem fatores comuns na clínica de pessoas com dependência de substâncias, isso indicou que a abordagem de educação popular deveria se estender também sobre os dias de produção e de reunião do grupo para autogestão, lançando mão de feedback e feedforward para favorecer a fixação e o exercício na prática cotidiana dos participantes. Esse processo configurou um novo momento do grupo, do projeto e da equipe do CAPS, os quais assumiram o desafio de operacionalizar tal produção. 


\section{Políticas públicas e economia solidária: entre propostas e estrutura pragmática}

Na primeira reunião voltada à estruturação do empreendimento solidário para a produção, realizada entre um dos extensionistas, P1 e P2 em 10 de agosto de 2018, foi verificada a inviabilidade de utilização, pelo empreendimento, da cozinha do CAPS, reservada para o uso exclusivo da equipe. Frente a isso, foi sugerida a busca de cozinha em espaço externo ao CAPS.

Neste processo, foi feita uma busca por cozinhas comunitárias nas adjacências. As ações Federais e Estaduais para Segurança Alimentar e Nutricional e Estaduais contavam, desde os anos 2000 até o momento desta conduta, com uma rede de equipamentos preconizados, a saber os bancos de alimentos, os restaurantes populares, as hortas comunitárias, as unidades de apoio a distribuição da agricultura familiar, as feiras livres e as cozinhas comunitárias. Estas são estratégias voltadas para o desenvolvimento de territórios com baixo Índice de Desenvolvimento Humano com o objetivo de promover a alimentação saudável, o trabalho e a geração de renda (Secretaria Nacional de Segurança Alimentar e Nutricional [SESAN], 2018; Tribuna do Paraná, 2005).

A partir da análise do censo Mapa de Segurança Alimentar e Nutricional (Mapa SAN), foram verificadas em Curitiba 40 feiras livres, sendo apenas 10 apoiadas pela prefeitura, mas nenhuma cozinha comunitária (Ministério do Desenvolvimento Social, 2015). Conflitantemente, entretanto, Miecoanski (2012) relatou a existência de 12 cozinhas comunitárias em Curitiba. A partir da inconsistência dos dados das referências e da impossibilidade de acesso a informações que operacionalizassem contatos institucionais, foi feito contato com a Organização da Sociedade Civil e com o poder executivo municipal, estadual e federal, responsáveis pela destinação e execução do recurso do governo federal reservado para este fim, mas não houve retorno relevante.

Em contato, os servidores do Governo Estadual informam que a antiga Secretaria do Trabalho, Emprego e Promoção Social foi dividida em duas e que o programa "Produza" e as cozinhas comunitárias, bem como políticas públicas referentes à Economia Solidária foram descontinuadas. O servidor [...] diz lembrar do programa e das cozinhas, mas ressalta que [...] os servidores da época foram dispensados ou remanejados, ficando apenas poucos como ele, que cumprem funções programáticas. Informam que não há mais nenhum acompanhamento destas cozinhas e que desconhece a situação deste equipamento, devido a conjuntura da gestão. O Poder Público Municipal alegou desconhecer tais equipamentos. Em telefonema, a Organização da Sociedade Civil responsável informou que não tinha ciência de nenhuma cozinha comunitária e que não [...] reconhece o trabalho da instituição junto a cozinhas comunitárias, não constando esta ação no histórico da entidade. Este último relato divergiu com as matérias publicadas à época a este respeito nos principais jornais em circulação em Curitiba (Sampaio, 14 de agosto de 2018).

Perante este cenário, a ação foi realinhada, lançando mão da Lei Ordinária Municipal no 14.786/16, que institui a Política Municipal de Fomento à Economia Popular Solidária e cria o Conselho Municipal de Economia Solidária. Segundo a lei, cabe ao poder executivo municipal, dentre outras atribuições, garantir a disponibilização de espaços, equipamentos e maquinários de propriedade do município e suas empresas controladas para o uso de empreendimentos solidários.

Desta forma, a Secretaria de Trabalho e Emprego (STE) foi contatada e demonstrou abertura para buscar e mediar parcerias para disponibilização de uma cozinha no Mercado Municipal de Curitiba ou em um Liceu de Ofício. Porém, a STE requereu o envio via e-mail de um projeto descritivo em papel timbrado acerca das ações pelo CAPS. Neste ponto, apesar de formalmente $\mathrm{C} 1$ ter aceitado pôr timbre no projeto redigido pelo extensionista, isso não se concretizou e esta parceria com a STE foi suspensa (Sampaio, 16 de agosto de 2018). Esta busca por uma cozinha aconteceu no período entre agosto e outubro de 2018, momento em que não havia sido sancionada a Lei Estadual de Economia Solidária no 19.784 de 2018.

Após o insucesso da parceria interinstitucional, foi tecida maior aproximação do extensionista com a coordenação e profissionais, e uma nova proposta foi apresentada. O extensionista sugeriu a utilização de um espaço para cozinha vago no imóvel do CAPS, e a captação de recursos para a equipagem do espaço. Com o aceite da equipe e da coordenação, foi feita 
uma lista e divulgado o projeto e as demandas de doações para igrejas, sinagogas, templos budistas, rádios, amigos, familiares, empresas privadas, redes sociais, maçonaria, Organizações Não-Governamentais, líderes comunitários e vereadores. Com a equipe mobilizada neste sentido, foram captadas doações de fogões, geladeira, microondas, liquidificador, panelas, tacho e diversos utensílios.

A coordenação pactuou ainda o compromisso de abastecer o grupo com o gás e, utilizando os armários do CAPS, forneceu cilindros de fechadura com chave para guardar os utensílios. Os insumos inicialmente foram patrocinados pela equipe, extensionista e pelos pacientes, sendo mantidos com o dinheiro das vendas a partir da primeira produção (Sampaio, 09 de janeiro de 2019).

Com isso, a constituição de um plano estratégico que integre políticas públicas em agendas programáticas de plano de ação em saúde mental, prestando suporte para iniciativas de reabilitação psicossocial como a inserção pelo trabalho e renda por meio da Economia Solidária, que em Curitiba e no Paraná possuem previsão em legislação, é um desafio para os gestores em saúde. A interação entre diversos atores de diferentes setores é necessária para a construção de uma rede de trabalho com maior potência para concretizar este trabalho. Além disso, a concessão de infraestrutura, apoio financeiro e logístico, formação e assessoria aos trabalhadores dos empreendimentos solidários e a definição de diretrizes de trabalho para profissionais que permitam parâmetros que facilitem estas ações devem ser uma construção conjunta.

\section{Produção e venda em discussão: entre o trabalho e a concretude}

Com o trabalho em rede mais alinhado, contando com apoio conjunto da equipe do CAPS, usuários, o extensionista e outros agentes, e uma cozinha equipada especialmente para o grupo, a prática encontra outro patamar para se desenvolver: o da produção e venda. Neste estágio, o grupo passou a pragmatizar os princípios e valores da Economia Solidária, tendo como base estrutural o empreendimento de culinária e, como horizonte, a geração de trabalho, renda e inclusão social. Neste novo momento, os processos de educação popular, antes fragmentados da prática do empreendimento, encontraram raiz e indissociabilidade junto ao processo de produção e trabalho.

O grupo foi organizado inicialmente em janeiro e fevereiro de 2019 para produção às segundas e sextas-feiras com P1 e P2 respectivamente, e nas quartas-feiras com o extensionista, como mediadores das relações no sentido da composição e do fortalecimento das reuniões de autogestão dos trabalhadores do empreendimento. A partir de março, o extensionista reorganizou com P1 e P2 as atividades do grupo, sendo segunda-feira e quarta-feira para produção e venda, e sexta-feira para reunião de autogestão do grupo, com P1, o extensionista e P2 respectivamente como referência para estes dias. Além disso, houve a inserção de uma discente voluntária no CAPS, incumbida de acompanhar as atividades e as estratégias de vendas para escoar a produção no período da tarde e nos demais dias da semana.

Tal processo foi, ainda, pactuado com a gestão do serviço, $\mathrm{C} 1$, construindo a rotina profissional da equipe para que P1 e P2 não ficassem sobrecarregados. A partir deste processo, a equipe passou a compreender o grupo de maneira diferente, especialmente $\mathrm{P} 3$ e P4, os quais prestaram contribuições técnicas diretas ocasionais voltadas a proporcionar suporte ao grupo.

Com o apoio e assessoria integradas de P1, P2 e dos recursos humanos próprios ao projeto de extensão, os quais dividiram esforços para mediar a iniciativa em cada um dos dias, foi possível fortalecer o empreendimento em diferentes de suas demandas, inclusive promovendo sua autogestão pelos usuários, agora trabalhadores.

A partir de março, o trabalho foi reorganizado, reservando as segundas e quartas-feiras para produção e venda e as sextas-feiras para reuniões de autogestão do grupo, com a presença de P1, do extensionista vinculado ao projeto e de P2, respectivamente, como referências para estes dias. Além disso, houve a inserção de uma estudante voluntária no CAPS, incumbida de acompanhar as atividades e as estratégias de vendas para escoar a produção no período da tarde e nos demais dias da semana. 
A produção começou com cozinha fria, tendo como produtos os sanduíches naturais. No desenvolvimento do processo, os trabalhadores do empreendimento organizaram esforços, conjuntamente com a equipe, para o início da produção de bolos de pote, bombons, empadão, bolos, brigadeiro entre outros. Entretanto, para a especialização das técnicas de produção, parcerias foram necessárias. Neste sentido, o apoio de instituições diversas, ONGs, redes sociais dos integrantes e de outros profissionais, como P3, contribuíram significativamente para esta etapa, possibilitando o acionamento de capacitações sobre determinadas técnicas de culinária.

Com o processo de desenvolvimento da iniciativa em andamento, diferentes situações passaram a compor seu cotidiano, assumindo a potência da indissociação de processos de Educação Popular, um dos pilares da Economia Solidária, da prática dos empreendimentos solidários. Desta forma, embora o processo possível, desenvolvido na sutil negociação entre projeto de extensão e CAPS, mediado pelas diferentes (im)possibilidades institucionais, tenha caminhado no sentido da promoção, em momento inicial, de um grupo com foco na educação popular para a Economia Solidária, ressalta-se a importância da integração indissociável entre práticas de educação popular e o cotidiano produtivo e de gestão do empreendimento, o que ampliaria, por certo, a compreensão pragmática dos princípios e valores da Economia Solidária e, possivelmente, a adesão dos usuários à iniciativa.

Nesta linha, ilustram o cenário, as ocasiões em que U34 pretendeu vender as mercadorias utilizando como estratégia a comoção dos clientes por conta de questões relacionadas ao transtorno mental, contrapondo-se às deliberações coletivas dos trabalhadores do empreendimento, ou quando U32 quis destituir as decisões do grupo nas reuniões de autogestão, impondo sua vontade sobre os demais. Ainda, dentre estes episódios, destaca-se a seguinte vivência:

Os usuários chegaram se queixando de U32 por não ter respeitado a posição de U12, mas pararam com os comentários quando ele chegou. Ao abordar o assunto com o grupo, houve tensão e, quando U12 ofereceu a função da contabilidade do grupo a U32, o restante do grupo expôs sua discordância. U32, por outro lado, diferentemente de outros momentos, não se inflamou, mas ao final disse que poderia manter um caderno paralelo para as contas do grupo, que aceitava a decisão da maioria em deixar U12 na função. Frente a isso, foi necessário reprisar os princípios da Economia Solidária, resgatando, de maneira aplicada, os conceitos de autogestão e democracia (Sampaio, 20 de fevereiro de 2019).

O manejo de falas e atitudes que ameacem ou descaracterizem as práticas no campo da Economia Solidária, devem ser conduzidos com atenção e cuidado, para não desmobilizar os envolvidos, e não incorrer o próprio profissional em um desacato às premissas éticas e teóricas deste trabalho. Nesta moldura, para Gontijo \& Paula (2019) o grande desafio no trabalho com os componentes de grupos de Economia Solidária está em uma reeducação coletiva que promova uma lógica cooperativa. A reflexão teórica é a base para as noções, compromissos e valorização dos princípios da Economia Solidária, e deve complementar a experimentação prática, pois dessa emerge a mudança de comportamento e sentimento a partir da vivência (Gontijo \& Paula, 2019). Neste processo, este enfrentamento para desarmar os integrantes uns em relação aos outros, desencorajar mecanismos de defesa de autossabotagem no grupo e incentivar as falas e práticas alinhadas a Economia Solidária, são procedimentos necessários no processo de estruturação prática dos grupos para administração, produção e vendas.

Além disso, a dificuldade em conseguir espaços protegidos para venda foi um grande obstáculo, pois se somou às demais dificuldades, reduzindo as possibilidades de injeção de capital proveniente do escoamento da produção e fizeram com que a sustentabilidade deste empreendimento solidário ficasse ameaçada, uma vez que a renda oriunda da divisão de lucros foi pequena. O espaço para a crítica e a autocrítica construtiva deve ser valorizado, pois acendem a pista de pouso dos pés no chão e podem orientar ações e o desenho de estratégias para fortalecer o empreendimento. 
Os usuários U5, U25 e U26 deixaram o grupo, ficando apenas 7 participantes (U12, U14, U21, U27, U32, U34 e U35), que já teve a participação de 35 pessoas ao longo do período de agosto de 2018 a março de 2019. Sobre isso, U14, membro do empreendimento, em reunião de autogestão afirmou: "sabe porque o pessoal sai do grupo assim...? É porque não vê dinheiro; não rola grana. Se rolasse, o pessoal ficava, mas é muito pouco. Você trabalha um dia com 10 pessoas pra conseguir 80 reais de lucro. Tirando o custo e rachando o dinheiro com todo mundo, não motiva ninguém" (Sampaio, 08 de março de 2019).

O baixo retorno financeiro, também experimentado por outras experiências em CAPS de Curitiba demonstram outro patamar de maturidade do grupo e de suas dificuldades, ou seja, se por um lado o grupo superou os desafios iniciais de estabelecer suas atividades e produção, por outro lado novos desafios como a rentabilidade, lucratividade, comércio justo e a manutenção da educação popular e dos princípios da Economia Solidária. Frente a isso, planejar o grupo para compor um fundo de caixa e posicionar-se em feiras livres da cidade divulgar o trabalho do grupo para receber encomenda para festas e coffee break e aproximar o grupo de coletivos como a Rede de Economia Solidária e Saúde Mental (LIBERSOL) para fortalecer o escoamento da mercadoria e aumentar a receita do empreendimento, assim como socializar experiências solidárias compõem novos horizontes para o cuidado em saúde mental que concretiza as interfaces que a atenção psicossocial preconiza. O manejo da ansiedade e da manutenção da coesão do grupo e do trabalho em rede é necessário e desperta um olhar e uma prática atenta e cuidadosa.

Para o enfrentamento e transformação da realidade, além destas estratégias, a prática da condução do grupo deve buscar auxiliar na elaboração de um plano de negócio, na organização do trabalho e suas dinâmicas, no planejamento do grupo para crescimento do empreendimento e em um processo contínuo de educação em Economia Solidária. Consoante Alvarez, Neves e Silva (2017), assim como a Reforma Psiquiátrica, a Economia Solidária avança apesar de seus impasses, tensões, conflitos e desafios. Potencializar seus vetores como produção de saúde, processo de trabalho, geração de renda, atividade e clínica, na intersecção entre estes dois campos é um desafio e possui seus próprios riscos e potências. Riscos como a emergência de um espaço mecânico e pouco reflexivo focado apenas em atividades laborais, assistencialismo, foco na produção de capital com enfraquecimento de relações interpessoais, ou potências como o real exercício da cidadania, autonomia, independência, reconhecimento pelo trabalho, sentimento de pertencimento, formação de vínculos na comunidade e a valorização de subjetividades e do coletivo são fatores a serem considerados nesta prática (Alvarez, Neves, \& Silva, 2017). Criar estratégias para reforçar e manter as potências e superar e prevenir barreiras estimula um trabalho conjunto a ser composto no cotidiano. Este cenário de prática expõe a necessidade de apoio e suporte institucional para este trabalho.

Em julho de 2019, o grupo contava com sete participantes, que se revezavam em escalas para produção e participação em duas feiras de duas Redes de Economia Solidária de Curitiba e Região. O grupo também buscou a articulação da inserção de seus produtos em outros pontos de venda, atribuindo ao empreendimento solidário também o papel de distribuidor.

\section{Conclusão}

A interface entre os campos da Saúde Mental e da Economia Solidária é caracterizada por diferentes barreiras que perpassam os ambientes institucionais e se estendem para complexas e diversas dimensões. Destinou-se aqui, esforços para apresentar as ações advindas de um projeto de extensão voltado a dar suporte a um empreendimento solidário situado neste campo confluente.

Neste processo, educação popular se faz necessária ao longo de toda a intervenção, sendo uma ferramenta para manutenção das diretrizes das ações dirigidas aos usuários permanentemente ancoradas na Economia Solidária. Uma abordagem inicial de educação popular em um empreendimento solidário em saúde mental previamente à produção e venda é necessária, e demanda planejamento prévio do período de acordo com o contexto. Com esta experiência, constatou-se que o 
processo de educação popular em Economia Solidária pode ser mais profícuo se associada organicamente a geração de renda e possibilidades de inclusão pelo trabalho. Isso permite a permeabilização e integração das atividades do grupo pelo processo de educação popular, que independentemente impõe ao profissional planejar e organizar seu trabalho com o grupo.

Assim, no processo da formação de arena para o desenvolvimento desta prática, é preciso costurar parcerias com a equipe e gestão do serviço, para origem de ambiente que viabilize a estruturação e manutenção de uma prática pautada na Economia Solidária. Para tanto, a conformação e sustentação de um trabalho em rede é imprescindível, uma vez que se institui como importante estratégia para a superação de barreiras diversas e para o reforço de potencialidades desta prática.

É fundamental que os profissionais de referência para estas ações não apenas se apropriem das políticas públicas que respaldam este trabalho, como também busquem proximidade de outras que possam reforçar suas ações abrindo portas para a inclusão pelo trabalho. Neste sentido, o desafio encontra-se na concretização do teor das políticas públicas, na mobilização de articulação interinstitucional e intersetorial, em arranjos institucionais e em procedimentos burocráticos.

Durante as atividades de produção e venda, abordagens grupais e individuais são necessárias para buscar efetividade em organização, sensibilização, direcionamento e circunscrição do grupo nos princípios da Economia Solidária. Em Saúde Mental, consoante a Economia Solidária, em atividades de venda no território, são necessárias ações de educação em saúde e sensibilização voltadas à comunidade e integrantes de redes de economia solidária para produzir uma real inserção e inclusão social dos participantes pelo trabalho. Além disso, o acompanhamento do grupo e seus componentes no desempenho de suas atividades de administração, produção e venda com promoção gradual de independência e autonomia é elementar.

Novas pesquisas com relatos de experiência metodologias e sistemáticas para o desenvolvimento de empreendimentos solidários em equipamentos públicos, considerando as dimensões pragmáticas estruturais, de pessoal, dinâmica de grupos, características territoriais e locorregionais, políticas públicas e mobilizações sociais diversas são necessárias para instrumentalizar profissionais em campo e formar recursos humanos para conduzir estas práticas.

\section{Referências}

Aguiar, J. L. C., \& Soares Filho, V. (2018). Políticas públicas de economia solidária: um estudo de caso na Prefeitura Municipal de Palmas/TO. Revista Humanidades e Inovação, 5(2), 70-79.

Almeida, L. A. P. I. (2018). Economia Solidária com foco em cooperativa de reciclagem de resíduos sólidos (Trabalho de Conclusão de Curso, Faculdade de Ciências Econômicas, Universidade do Sul de Santa Catarina). Recuperado de http://www.riuni.unisul.br/handle/12345/5516.

Alvarez, A. P. E., Neves, C. E. A. B., \& Silva C. O. (2017). Saúde mental e economia solidária: pesquisa cartográfica em um dispositivo clínico-político. CBSM, 9(22), 124-144.

Amarante, P., \& Nunes, M. O. (2018). A reforma psiquiátrica no SUS e a luta por uma sociedade sem manicômios. Ciênc. saúde coletiva., 23(6), 2067-2074.

Araújo, A. K., \& Soares, V. L. (2018). Trabalho e saúde mental: relato de experiência em um CAPS AD III na cidade de João Pessoa, PB. Saúde Debate, 42(Especial 4), 275-284.

Pereira A. S. et al. (2018). Metodologia da pesquisa científica. [free e-book]. Santa Maria/RS. Ed. UAB/NTE/UFSM.

Brasil. Casa Civil. Decreto $\mathrm{n}^{\circ}$ 7.508, de 19 de setembro de 1990. (1990). Regulamenta a Lei $n^{\circ}$ 8.080, de 19 de setembro de 1990, para dispor sobre a organização do Sistema Único de Saúde - SUS, o planejamento da saúde, a assistência à saúde e a articulação interfederativa, e dá outras providências. Diário Oficial da União, 29 jun 2011.

Brasil. Casa Civil. Lei ${ }^{\circ}$ 8.080, de 19 de setembro de 1990. (1990). Dispõe sobre as condições para a promoção, proteção e recuperação da saúde, a organização e o funcionamento dos serviços correspondentes e dá outras providências. Diário Oficial da União, 20 set 1990.

Brasil. Ministério da Saúde. Portaria $\mathrm{n}^{\circ}$ 121, de 25 de janeiro de 2012. (2012). Institui a Unidade de Acolhimento para pessoas com necessidades decorrentes do uso de Crack, Álcool e Outras Drogas (Unidade de Acolhimento), no componente de atenção residencial de caráter transitório da Rede de Atenção Psicossocial. Diário Oficial da União, 25 jan 2012.

Brasil. Ministério da Saúde. Portaria no 130, de 26 de janeiro de 2012. (2012). Redefine o Centro de Atenção Psicossocial de Álcool e outras Drogas 24 h (CAPS AD III) e os respectivos incentivos financeiros. Diário Oficial da União, 27 jan 2011. 
Brasil. Ministério da Saúde. Portaria n $\mathrm{n}^{\circ}$ 131, de 26 de janeiro de 2012. (2012). Institui incentivo financeiro de custeio destinado aos Estados, Municípios e ao Distrito Federal para apoio ao custeio de Serviços de Atenção em Regime Residencial, incluídas as Comunidades Terapêuticas, voltados para pessoas com necessidades decorrentes do uso de álcool, crack e outras drogas, no âmbito da Rede de Atenção Psicossocial. Diário Oficial da União, 27 jan 2012.

Brasil. Ministério da Saúde. Portaria no 3.088, de 23 de dezembro de 2011. (2011). Institui a Rede de Atenção Psicossocial para pessoas com sofrimento ou transtorno mental e com necessidades decorrentes do uso de crack, álcool e outras drogas, no âmbito do Sistema Único de Saúde (SUS). Diário Oficial da União, 26 dez 2011 .

Brasil. Ministério da Saúde. Portaria de Consolidação nº 3, de 28 de setembro de 2017. (2017). Consolidação das normas sobre as redes do Sistema Único de Saúde. Diário Oficial da União, 28 set 2017

Brasil. Ministério da Saúde. Portaria no 3.588, de 21 de dezembro de 2017. (2017). Altera as Portarias de Consolidação no 3 e $n^{\circ}$ 6, de 28 de setembro de 2017, para dispor sobre a Rede de Atenção Psicossocial, e dá outras providências. Diário Oficial da União, 22 dez 2017.

Damasceno, N. F. P., Malvezzi, E., Sales, C. M., \& Sales, A. (2018). A narrativa como alternativa na pesquisa em saúde. Interface (Botucatu), 22(64), 133-40.

Ferreira, F. M. (2018). Economia solidária: um estudo sobre as incubadoras públicas municipais (Dissertação de mestrado, Programa de Pós-Graduação em Administração Pública, Universidade Federal de Goiás). Recuperado de http://repositorio.bc.ufg.br/tede/handle/tede/8510.

Ferro, L. F., Franzoloso, C. L. S., \& Burnagui, J. G. (2021). Redes de Economia Solidária: estratégias para a captação de recursos. REU, 46(2), 469-495.

Gontijo, F. M. C., \& Paula, A. P. P. (2019). Os sentidos da economia solidária: reflexões sobre um curso de formação. Educ. Pesqui., 45 ;e185054.

Lima, M. G., Gussi, M. A., \& Furegato, A. R. F. (2018). Centro de Atenção Psicossocial, o cuidado em saúde mental no Distrito Federal, Brasil. Tempus, actas de saúde colet., 11(4), 197-220.

Martins, L. A. S., Oliani, F. S., \& Riffel, C. M. (2017). Tecendo redes de solidariedade: uma aposta de fortalecimento da economia solidária na Região da Foz do Rio Itajaí/SC. Florianópolis, SC: Insular.

Mazucato, T., Zambello, A. V., Soares, A. G., Tauil, C. E., Donzelli, C. A., Fontana, F., \& Chotolli, W. P. (2018). Metodologia da Pesquisa e do Trabalho Científico. Penápolis, (SP): FUNEPE.

Medeiros, A. J. S., Vilaça, M., Nunes, J., Dubeux, A. (2018). Economia solidária, educação popular e a pedagogia da autogestão: reaprendendo a viver pelas veredas da descolonização do saber do nordeste. Coletânia educação popular e economia solidária no nordeste. Olinda, PE: MXM Gráf. Ed..

Miekoanski, E. (2012, 10 de outubro). Cozinha que gera renda, mata a fome e dá saúde. Gazetadopovo.com.br. https://www.gazetadopovo.com.br/vida-ecidadania/cozinha-que-gera-renda-mata-a-fome-e-da-saude-2ecdo3z6gbuj9m031sbgwtc9a.

Ministério do Desenvolvimento Social (2015). MapaSAN 2015. Aplicações. Equipamentos Públicos de Segurança Alimentar e Nutricional. https://aplicacoes.mds.gov.br/sagi/simulacao/mapasan/lista/censosanLista.php?ano=2015.

Moraes, R. C. P.,\& Castro-Silva, C. R. (2016). Sentidos e Processos Psicossociais envolvidos na Inclusão pelo Trabalho na Saúde Mental. Psicol., Ciênc. Prof. (Impr.), 36(3), 748-762.

Nagem, F. A., \& Jesus, S. A. (2013). V Plenário nacional de economia solidária: trajetória e construção da economia solidária no Brasil (Relatório do Instituto de Ciência Econômica Aplicada). Brasília, DF: Ipea.

Oliveira, F. B., Moreira, M. R. C., Lima Junior, J. F. L., Nascimento, D. C., Silva, F. M. S., \& Antunes J. (2018). Articulação das políticas públicas de saúde mental e economia solidária - iniciativas de geração de trabalho e renda. HOLOS, 6(34), 130-140.

Righi, L. B., \& Gonçalves, C. H. (2018). Cartografia e Hermenêutica nos Enlaces da Pesquisa Participativa. Rev. Polis e Psique., 8(1), $132-143$.

Sampaio, F. R. R. (2019). Diário de Campo: eventos de pesquisa de 22 de março de 2018 até 12 de agosto de 2019. Curitiba, PR: Sampaio.

Santos, C. V. (2018). Evolução da produção científica em economia solidária: o cenário brasileiro. ORG \& DEMO, 19(1), 97-112.

Santos, S. C. (2017). Jogos cooperativos e jogos competitivos: manifestações de suas características em um ambiente educativo (Dissertação de Mestrado, Faculdade de Ciências Humanas, Universidade Metodista de Piracicaba). https://iepapp.unimep.br/biblioteca_digital/visualiza.php?cod=MTc0Mg==.

Secretaria Nacional de Segurança Alimentar e Nutricional. (2018). Princípios e Práticas para Educação Alimentar e Nutricional. Brasília, DF: Ministério do Desenvolvimento Social.

Silva, F. J. S. (2018). Jogos cooperativos como ferramenta pedagógica para as aulas de educação física. Revista Carioca de Educação Física., 13(1), 34-46.

Silva, S. P. (2020). Dinâmicas da economia solidária no Brasil: organizações econômicas, representações sociais e políticas públicas. Brasília, DF: IPEA

Souza, A. R., \& Augusto Júnior. F. (2020). A economia solidária como resposta à crise pandêmica e fator de outro tipo de desenvolvimento. p2p, 7(1), 8-25.

Tribuna do Paraná. (2005, 03 de agosto). Secretaria do Trabalho conclui entrega de 28 cozinhas comunitárias. Tribunapr.com.br. https://www.tribunapr.com.br/noticias/secretaria-do-trabalho-conclui-entrega-de-28-cozinhas-comunitarias/. Acesso em: 14 de julho de 2021.

Vitale, C. M. F. L., \& Silva, L. A. M. G. (2017). Aplicação da Teoria dos Jogos na mediação de conflitos: o Equilíbrio de Nash como estratégia de maximização de ganhos. Revista FONAMEC., 1(1), 94-110. 